vs. PhGl was $-21.9 ; 69.5$ [23.8], for PaGl vs. pain $-17.1 ; 22.0$ [4.9], and for PhGl vs pain $-60.8 ; 23.0[-18.9]$.

Conclusions: In patients with PsA, PaGl was in general scored considerably higher than PhGl. The two scores were poorly connected not only on the individual level but also on group level with no systematic differences between the scores. PaGl was best predicted by pain, and PhGl by SCJ reflecting patients and physicians diverging attitudes to the importance of the different disease manifestations. The findings highlight the challenge of understanding and dealing with discrepancies between assessments and attitudes by physicians and patients.

Disclosure of Interest: None declared

DOI: 10.1136/annrheumdis-2017-eular.4092

\section{AB0779 CLINICAL MANIFESTATIONS AND PARAMETERS AFFECTING THERAPEUTIC RESPONSE IN A COHORT OF 411 PSORIATIC ARTHRITIS PATIENTS}

M.P. Migkos, T.-E. Memi, T.E. Markatseli, A.A. Drosos, P.V. Voulgari. Rheumatology Clinic, Department of Internal Medicine, Medical School, University of loannina, Ioannina, Greece

Background: Psoriatic arthritis (PsA) has various clinical manifestations. The therapeutic response of patients may be affected by epidemiological parameters such as body mass index (BMI), disease duration, sex and the choice of therapy. Objectives: To illustrate the clinical manifestations of psoriatic arthritis and to assess the impact of epidemiological features and treatment choice on therapeutic response.

Methods: We retrospectively studied 411 patients diagnosed with PsA and we recorded the clinical manifestations of the disease. Data of 254 out of 411 patients were analyzed to examine the possible effect of BMI, disease activity, sex and treatment choice on therapeutic response. Patients were followed up at predefined time points [baseline, 12 weeks (wks), 24 wks, 48 and 240 wks after initiation of therapy]. The treatment response was assessed using Bath Ankylosing Spondylitis Disease Activity Index (BASDAI), Bath Ankylosing Spondylitis Functional Index (BASFI), disease activity score-28 (DAS) -C-Reactive Protein (CRP), DAS28erythrocyte sedimentation rate (ESR) and Health Assessment Questionnaire (HAQ). Patients were categorized in three groups: patients treated with biological synthetic disease modifying anti-rheumatic drugs (DMARDs) (anti-tumor necrosis factor alpha (TNFa) agents), patients treated with synthetic DMARDs and combined therapy (biological and synthetic DMARDs).

Results: The interval between psoriasis and PsA in women is shorter $(p=0,041)$. PsA presented predominantly as asymmetric oligoarthritis $(41,60 \%)$, followed by symmetric polyarthritis $(24,57 \%)$. Arthritis of distal phalangeal joints was established in $3,16 \%$, while $4,37 \%$ showed only enthesitis or dactylitis. Axial involvement was recorded in $26,27 \% 7$. Twenty-eight patients had only axial disease and 80 had axial and peripheral joint involvement. 23/411 patients $(5,60 \%)$,had eye involvement, $8 / 411(1,95 \%)$ and $6 / 411(1,46 \%)$ had involvement of the urogenital and gastrointestinal system, respectively. Eleven patients had pulmonary fibrosis. In the subgroup analysis of 254 patients, disease duration was positively correlated in all time points $(p<0,005)$ with all disease activity scores. Statistical significant differences with respect to gender was observed for DAS28-CRP $(3,93-2,96,3,54-2,64 p<0,001)$ and DAS28-ESR $(3,37-2,82$ $\mathrm{p}=0,001,3,06-2,62 \mathrm{p}=0,023)$ at 12 and 24 wks respectively. More specifically women showed higher disease activity than males the first 6 months after treatment. BMI was not significantly correlated with the disease activity. Treatment with biological DMARD showed a statistically significant difference in all disease activity scores early in the disease course $(p<0,05)$ in comparison with those receiving conventional DMARD. After the first 12 wks all disease activity scores were rather stable with no differences between the treatment groups.

Conclusions: PsA manifests predominantly as asymmetric oligoarthritis. Extraarticular manifestations are less frequent. Higher disease duration was associated with higher disease activity. Women early on disease course had higher DAS-28 scores. Treatment with biological DMARD showed better response in PsA patients compared with synthetic early in the disease course. However, after the first 12 wks there were no significant differences in treatment response with respect to treatment choice.

Disclosure of Interest: None declared

DOI: 10.1136/annrheumdis-2017-eular.4784

\section{AB0780 SECUKINUMAB SUSTAINS INDIVIDUAL CLINICAL RESPONSES OVER TIME IN PATIENTS WITH PSORIATIC ARTHRITIS: 2-YEAR RESULTS FROM A PHASE 3 TRIAL, FUTURE 2}

P. Emery ${ }^{1}$, I.B. Mclnnes ${ }^{2}$, P.J. Mease ${ }^{3}$, M. Schiff ${ }^{4}$, L. Pricop ${ }^{5}$, S. Shen ${ }^{5}$, Z. Wang ${ }^{5}, \mathrm{C}$. Gaillez ${ }^{6}$ on behalf of the FUTURE 2 study group. ${ }^{1}$ University of Leeds, Leeds; ${ }^{2}$ University of Glasgow, Glasgow, United Kingdom; ${ }^{3}$ Swedish Medical Centre and University of Washington, Seattle; ${ }^{4}$ University of Colorado, Denver; ${ }^{5}$ Novartis Pharmaceuticals Corporation, East Hanover, United States; ${ }^{6}$ Novartis Pharma AG, Basel, Switzerland

Background: Achieving sustained clinical response to biologics is part of treatto-target recommendations in psoriatic arthritis (PsA) and is aimed at optimising treatment goals.
Objectives: To evaluate patient (pt)-level secukinumab data and report the likelihood of improving, sustaining or worsening of American College of Rheumatology (ACR) response and disease status (disease activity score 28 based on C-reactive protein [DAS28-CRP]) from Week (Wk) 24 to 104 in pts with active PsA from the FUTURE 2 trial. 2,3

Methods: The findings of the FUTURE 2 trial through Wk 104 have been previously reported. ${ }^{3}$ Post-hoc shift analyses were performed on ACR response between Wks 24 and 104 for subgroups of secukinumab-treated pts, based on their higher response rate at an earlier time point in 1 out of 4 categories (ACR non-responders [NR], ACR20, 50 or 70) by evaluating whether the response improved, sustained or worsened at a later time point using exclusive categories and as observed analyses. Similar shift analysis on DAS28-CRP derived criteria were performed in 4 exclusive categories extrapolated from rheumatoid arthritis: high, moderate, low disease activity (HDA, MDA, LDA) or remission (REM) only. ${ }^{4}$ Results: In total, 86/100 (86\%) and 76/100 (76\%) pts in the secukinumab 300 and $150 \mathrm{mg}$ groups, respectively, completed the 104-wk treatment. Of which, 73/70 and $81 / 75$ pts in secukinumab $300 / 150 \mathrm{mg}$ were eligible for ACR and DAS28CRP shift analysis, respectively, from Wk 24 to 104 . Baseline demographics and clinical characteristics were balanced across the two dose groups. ${ }^{2,3}$ Most secukinumab-treated pts who achieved at least an ACR20, 50 or 70 response and Psoriasis Area and Severity Index (PASI) 75 or 90 response at Wk 24, improved or sustained their response at Wk 104 (Figure, data not shown for PASI response). Similarly, a majority of pts who were in the MDA, LDA or REM category at Wk 24 sustained or improved their disease status related to DAS28-CRP score at Wk 104 (Figure).

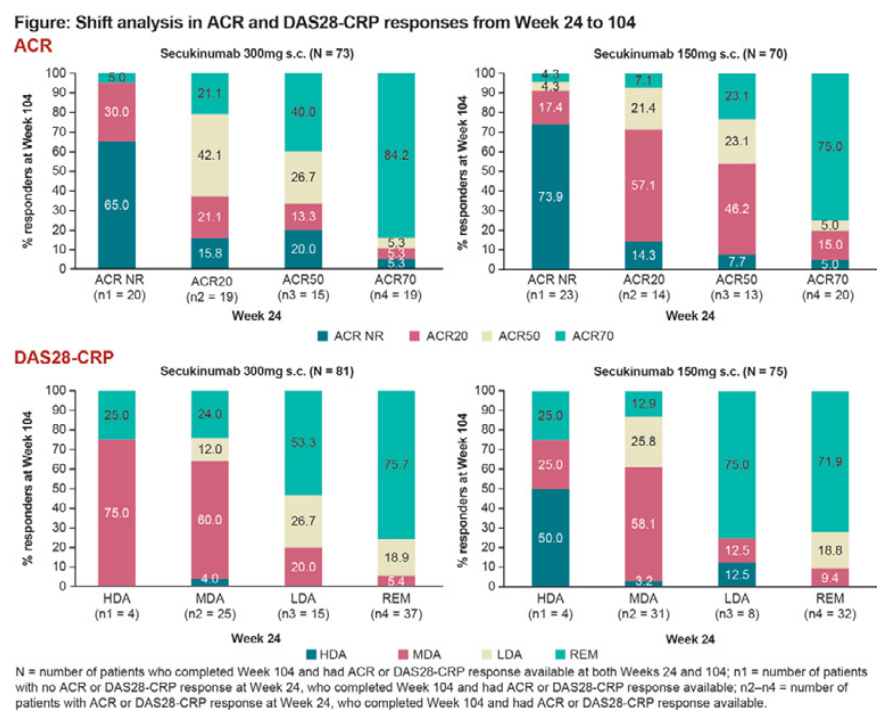

Conclusions: In this post-hoc analysis, a majority of secukinumab-treated pts who achieved at least ACR20 and PASI 75 response or at least MDA at Wk 24 sustained or improved their ACR and PASI responses or sustained or reduced their disease status at Wk 104. Numerically higher sustained response and LDA or REM rate was observed for secukinumab $300 \mathrm{mg}$, thereby extending the sustainability of response and lowering the disease activity that has been previously reported at group level..$^{2,3}$

References:

[1] Gossec L, et al. Ann Rheum Dis 2016;75:499-510.

[2] McInnes IB, et al. Lancet 2015;386:1137-46.

[3] McInnes IB, et al. Arthritis Rheumatol 2016;68;abstract: 2757.

[4] Wells G, et al. Ann Rheum Dis 2009;68:954-60.

Disclosure of Interest: P. Emery Consultant for: AbbVie, BMS, Merck, Novartis, Pfizer, Roche, UCB, I. Mclnnes Consultant for: Novartis, Amgen, Janssen, BMS, Pfizer, UCB, Abbvie, Celgene, Lilly, P. Mease Grant/research support from: AbbVie, Amgen, Biogen Idec, BMS, Celgene, Crescendo, Janssen, Lilly, Merck, Novartis, Pfizer, UCB, Consultant for: AbbVie, Amgen, Biogen Idec, BMS, Celgene, Covagen, Crescendo, Janssen, Lilly, Merck, Novartis, Pfizer, UCB, Speakers bureau: AbbVie, Amgen, Biogen Idec, BMS, Crescendo, Janssen, Lilly, Pfizer, UCB, M. Schiff Consultant for: Abbvie, BMS, Lilly, J\&J, Speakers bureau: Abbvie, L. Pricop Shareholder of: Novartis, Employee of: Novartis, S. Shen Employee of: Novartis, Z. Wang Employee of: Novartis, C. Gaillez Shareholder of: Novartis, BMS, Employee of: Novartis

DOI: 10.1136/annrheumdis-2017-eular.1228 